\title{
Professional Development
}

\section{Psychological Climate, Stress, and Research Integrity Among Research Counselor Educators: A Preliminary Study}

\author{
Kelly L. Wester, John T. Willse, \& Mark S. Davis
}

\begin{abstract}
In this quantitative study, 187 counselor educators at research institutions reported engaging in responsible conduct of research (RCR), with a few individuals reporting deviations from ethical behavior. Tenure-seeking faculty members indicated a greater likelihood of deviating from acceptable research practices than did tenured faculty members. The psychological meaningfulness of one's department and research ethics training positively related to engagement in RCR, explaining $18 \%$ of the variance. Implications for training of research ethics are discussed, along with suggestions for environmental needs within counseling departments to potentially increase psychological meaningfulness for faculty members.
\end{abstract}

The pursuit of knowledge in the form of research is one method university faculty members use to enhance their professional status and recognition through publications as well as to gain grant funding. Research and professional status are also criteria many institutions use to decide promotion and tenure. This reliance on research may increase stress, which in turn may lead individuals to deviate from acceptable practices of research (De Vries, Anderson, \& Martinson, 2006). These deviations can range from questionable research practices (GRPs; e.g., inappropriate authorship, fishing data for significant results) to research misconduct (e.g., plagiarism, falsification of data). Deviations from acceptable research practices can lead, minimally, to public and peer distrust in research findings and may also cause serious harm to research participants. To minimize or prevent deviations from responsible research, the profession must first understand the amount of QRPs that exist and the factors that cause or relate to these departures.

We examined a model that compared the relationships between levels of perceived stress, life stressors, departmental psychological climate, and training in research ethics on research university counselor educators' responsible conduct of research (RCR). In addition, we sought differences in RCR on the basis of tenure status. Before exploring this

Kelly L. Wester, Department of Counseling and Educational Development, and John T. Willse, Department of Educational Research Methodology, University of North Carolina at Greensboro; Mark S. Davis, Criminal Justice Research Center, Ohio State University. Correspondence concerning this article should be addressed to Kelly $L$. Wester, Department of Counseling and Educational Development, School of Education, University of North Carolina at Greensboro, PO Box 26170, Greensboro, NC 27402 (e-mail: klwester@uncg.edu). 
model among counselor educators conducting research, we provide a brief explanation of research integrity and the known related factors.

Research integrity has been defined as adhering to moral principles, professional standards, and commonly accepted ethical codes in the area of research (Steneck, 2006; U.S. Department of Health and Human Services [HHS], National Institutes of Health [NIH], Office of Extramural Research, 2002). For counseling professionals, this means adhering to Section G of the ACA Code of Ethics (American Counseling Association [ACA], 2005). In addition, the ethical codes for any professional organization of which a counselor might be a member (e.g., state licensure boards, National Board for Certified Counselors) should be followed. When researchers deviate from these accepted norms or ethical codes, they are considered to be engaging in QRPS (Steneck, 2003) or, more seriously, research misconduct (HHS, Office of Research Integrity, 2000). Steneck (2003) suggested that $10 \%$ to $40 \%$ of research within the broader research community could fall under QRPs, whereas the prevalence of research misconduct occurs at a lesser rate of 1 per 100,000 researchers.

The field of counseling is not exempt from QRPs and research misconduct, and rates of deviant behavior seem to fit within, or below, Steneck's (2003) suggested range. Over the past 10 years, ACA reported approximately $1 \%$ of informal inquiries to the ethics committee related to research and publication practices (e.g., Brown \& Espina, 2000; Kocet \& Freeman, 2005; Sanders \& Freeman, 2003). In addition, Davis, Wester, and King (2008) conducted a study asking members of the Association for Counselor Education and Supervision to respond to eight case vignettes related to research integrity. Specifically, study participants indicated the likelihood of their engaging in the same behavior as the researcher in the vignette. Davis et al. (2008) found that between $1 \%$ and $24 \%$ of counselor educators, practitioners, and doctoral students self-reported a likelihood to deviate from RCR. More specifically, they found that $2.5 \%$ of counseling professionals indicated they would use inappropriate deception in their research, $14.8 \%$ would publish a manuscript as the sole author when another person had contributed significantly to the analysis and writing of the manuscript, and $20 \%$ reported they would provide ghost authorship on a presentation. Furthermore, Davis et al. (2008) found that $8 \%$ of counseling professionals would be likely to report inaccurate statistical results for personal gain; that is, they self-reported their likelihood to falsify data and engage in research misconduct.

Although Davis et al.'s (2008) study presented an initial look at what occurs regarding research integrity, the profession needs to know more to understand why such behaviors occur. An understanding of QRPs and research misconduct might help to temper the behavior or eliminate it altogether. However, we found very little documentation regarding potential causes of unethical research behavior. Much of the available literature concerns the practices of biomedical scientists and psychology students. Of those factors examined, researchers have predominantly explored integrity in general and not research 
integrity specifically (e.g., Mumford, Connelly, Helton, Strange, \& Osburn, 2001). From the findings presented in the literature, factors relating to general integrity include individual characteristics (e.g., stress management; Mumford \& Helton, 2002), situational circumstances (e.g., levels of stress, pressures to publish; Rees, 2001), and organizational aspects (e.g., departmental climate, meaningfulness at work; Anderson, 1996; Anderson, Louis, \& Earle, 1994).

Relating specifically to research integrity, Davis, Riske, and Seaman (2001) conducted qualitative interviews with researchers found guilty of research misconduct. Davis et al. (2001) found that one of the main factors reported as a cause of deviation from accepted practice was a high level of stress. This relationship was also hypothesized by Mumford and Helton (2002), who conjectured that individuals experiencing stress and overload would engage in unethical behavior more frequently.

Anderson (1996) found that psychological climate (i.e., the perception and meaning that individuals attach to their work environments) at the department level was related to QRPs. More specifically, graduate students in this study reported a lack of training in research ethics and observation of multiple incidents of misconduct within their departments. Thus, a combination of lack of training in research ethics, along with deviation from RCR, may create a normative system that lacks research ethics. Martinson, Anderson, Crain, and De Vries (2006) examined factors related to QRPs in a group of NIH grant awardees. Martinson et al. found that perceived violations in procedural justice positively related to self-reported misbehavior in research. Thus, a sense that one is treated unfairly or not recognized for contributions to the department may lead to cutting corners in research. Specifically related to counselor educators, Davis et al. (2008) found narcissism positively related to QRPS and research misconduct; however, this relationship was weak (i.e., $r=.21, r^{2}=.04$ ).

On the basis of reviewed literature, we found that very little is known regarding factors related to deviations of RCR. Given what is known, we found that most researchers examined only one or two potential factors at a time that might relate to research integrity-ignoring the complexity that exists in making ethical decisions (Rest \& Narváez, 1994). A combination of factors working together may play a role in researchers making decisions in research.

The goal of this study was to explore research integrity among counselor educators engaged in research, specifically examining the perceived likelihood of engaging in QRPs and research misconduct and the correlates of these behaviors. We examined three specific research questions and formulated corresponding hypothesis:

1. What is the likelihood of counselor educators engaging in research misconduct and GRPs? We hypothesized that, similar to other estimates, the majority of counselor educators will report engaging in RCR.

2. Do significant differences exist between counselor educators seeking tenure, those already tenured, and those currently not on 
the tenure track in likelihood to engage in research misconduct and QRPs? We hypothesized that significant differences will exist because of the potential stressors that tenure-seeking faculty members experience.

3. Does a relationship exist between departmental psychological climate, life stressors, perceived stress, and RCR, controlling for training in research ethics? We hypothesized that a significant relationship will exist between psychological meaningfulness and safety, perceived stress, and training in research ethics and RCR.

\section{Method}

\section{Procedure}

We used a stratified cluster and random sampling method. To define the strata, we used the Doctorate-granting Universities category of the Basic Classification from the Carnegie Classification system (Carnegie Foundation for the Advancement of Teaching, n.d.; see http:// www.carnegiefoundation.org/ for further information regarding the Carnegie Classifications). The Doctorate-granting Universities category has three levels: RU/VH: Research Universities (very high research activity), RU/H: Research Universities (high research activity), and DRU: Doctoral/Research Universities. We selected research universities because of the assumption that most faculty members would be conducting research. Once we defined strata, we randomly selected 49 universities from both the $\mathrm{RU} / \mathrm{VH}$ and $\mathrm{RU} / \mathrm{H}$ strata and used all 28 universities in the DRU stratum.

We examined the websites of the selected universities to determine whether counselor education programs existed. Of the 126 universities across the three research strata, 109 universities had counselor education programs (i.e., 49 for $\mathrm{RU} / \mathrm{VH}, 35$ for $\mathrm{RU} / \mathrm{H}$, and 25 for DRU). We downloaded the counselor educator program faculty member listings from the corresponding websites. Because five programs did not provide faculty member information online, we removed these programs from the sample.

The final pool consisted of 104 programs with 727 faculty members. We sent each faculty member an invitation via e-mail to participate in an online survey of faculty life, departmental experiences, and research experiences. Those who did not respond to the initial e-mail received up to two additional e-mails, sent 2 weeks apart. Faculty members were offered the opportunity to enter themselves into a raffle to receive $\$ 50$. This study was approved by the institutional review board (IRB).

\section{Participants}

Of the 727 e-mails sent to faculty members in the sampling pool, 31 were undeliverable. Among the 696 faculty members who received invitations, 263 responded, resulting in a response rate of $37.8 \%$. We screened these 263 faculty members according to the original criteria for the inclusion in the study: (a) being a counselor educator (i.e., individuals were employed in counselor education programs, yet they 
indicated that they were trained in another discipline or did not identify as a counselor educator) and (b) participating in research within the past 5 years. By applying these screening criteria, we ensured that faculty members had participated in research, which was defined as but not limited to mentoring students in research, reviewing articles for publication, developing research ideas, conducting various forms of research (e.g., qualitative and quantitative), collecting data, analyzing data, and writing research results. We found that 76 of the 263 who responded did not meet the inclusion criteria, and we removed them from the final sample that we used in our data analysis.

The final sample consisted of 187 counselor educator faculty members from research-classified universities. Power analyses indicated that a sample of 66 was needed to have a power of .80 and a moderate effect size of . 40 to compare groups in the current study. The final sample size of 187 had sufficient power to determine whether significant differences existed in the current sample. For the path analysis, 10 participants per estimated parameter is considered the general rule (Kline, 2005). A sample of 140 would have been sufficient for our model with six variables and containing 14 estimated parameters.

More than half of the final sample of counselor educator faculty members were women (56.7\%); $41.7 \%$ were men, and $1.6 \%$ did not indicate sex. Regarding self-reported ethnic/racial identity, $79.1 \%$ of the participants were Caucasian, $8.0 \%$ African American, 3.7\% Asian/Asian American, 2.1\% Hispanic/Latino, 1.6\% Native American, $2.7 \%$ multiracial, and $2.7 \%$ other. More than half of the participants were tenured faculty members $(54.0 \%) ; 32.6 \%$ were seeking tenure, $12.3 \%$ were not on the tenure track, and $1.1 \%$ did not indicate tenure status. Of those on the tenure track (seeking tenure or tenured), $36.4 \%$ were assistant professors, $31.5 \%$ associate professors, $31.5 \%$ full professors, and $0.6 \%$ emeritus professors. Those faculty members not on the tenure track were instructors, lecturers, adjunct faculty, clinical professors, and emeritus professors. Approximately equal numbers of faculty members came from the three research strata: $32.6 \% \mathrm{RU} / \mathrm{VH}, 37.4 \% \mathrm{RU} / \mathrm{H}$, and $28.3 \% \mathrm{DRU} ; 1.6 \%$ did not indicate the university's research strata. Using a $z$ test comparing sample proportions, we found that the demographics of our study's final sample are similar to those of other studies regarding counselor educators published in Counselor Education and Supervision.

\section{Instruments}

The web-based survey contained a screening question to eliminate individuals who had not engaged in research during the past 5 years. As indicated in the Participants section, we excluded from our study those individuals who indicated that they had not engaged in research within the past 5 years. The remainder of the survey included several measures.

Demographics. Participants self-reported their sex, age, race, academic rank, tenure status, research productivity (e.g., how many publications and presentations they have had within the past 2 years), and aver- 
age amount of time spent per week advising or mentoring students. Participants also indicated their training in research ethics.

$R C R$. We used the Responsible Conduct of Research Measure (RCRM; Wester, Willse, \& Davis, 2008) to measure the self-reported likelihood that researchers depart from or engage in RCR. The RCRM consists of 42 items depicting research activities that are based on the HHS Office of Research Integrity's RCR areas. Participants respond to each item using a 6-point Likert-type scale, ranging from 1 (extremely unlikely) to 6 (extremely likely), indicating the likelihood that they would engage in the behavior. Scores are summed (possible range of 42 to 252), with higher scores indicating a greater likelihood of engaging in RCR and lower scores indicating the likelihood of engaging in QRPs or research misconduct. As a way to guard against response bias (Converse \& Presser, 1986), 19 of the 42 items are reverse scored. Wester et al. (2008) found that the RCRM has adequate reliability (Cronbach's $\alpha>.80$ ); construct validity; and a nonsignificant, low correlation with measures of social desirability. Cronbach's alpha for the current study was .81 .

Perceived stress. We used the Perceived Stress Scale (PSS; Cohen, Kamarck, \& Mermelstein, 1983) to measure the degree to which individuals appraise situations in their lives as stressful. The fouritem PSS was used to assess participants' levels of perceived stress. Participants respond to each item using a 5-point Likert-type scale, ranging from 0 (never) to 4 (very often), indicating how often they have felt a certain way in the past month. Cohen et al. (1983) found that the four-item PSS has adequate reliability (Cronbach's $\alpha=.72$ ) and validity. Cronbach's alpha for the current study was .82 .

Stressful life events. We used the revised 14-item version of the Holmes-Rahe Social Readjustment Rating Scale (SRRS; Scully, Tosi, \& Banning, 2000) to assess the most recent life events (e.g., pregnancy, divorce, job loss) that have occurred in individuals' lives and the effects of those events. Participants indicate whether they have experienced a specific life event within the past 12 months. For those events that they have experienced, participants indicate the extent to which they were affected by that event using a 7-point Likert-type scale, ranging from 1 (no impact) to 6 (overwhelming impact), with 0 being not applicable. Scores are summed and divided by the number of incidents reported. Higher scores on the SRRS indicate higher levels of stressful life events and greater impact.

Departmental psychological climate. We used the Psychological Climate Scale (PCS; Brown \& Leigh, 1996) to assess the way in which individuals perceive their departmental environment. The 21-item PCS yields one composite score of psychological climate, with two second-order factors: Psychological Safety and Psychological Meaningfulness. Psychological Safety measures an individual's sense of being able to show and employ oneself without fear of negative effects (Kahn, 1990). Psychological Meaningfulness has been defined as a feeling that one receives as a return on investments of one's time and energy (Kahn, 1990). Participants respond to each item using a 7-point Likert-type scale, ranging from 1 (strongly 
disagree) to 7 (strongly agree), indicating the extent to which they agree with the statement. Cronbach's reliability coefficients for the PCS have ranged between .73 and .83 (Brown \& Leigh, 1996; Kiewitz, Hochwarter, Ferris, \& Castro, 2002). The PCS has also been found to be valid (Brown $\&$ Leigh, 1996). We found that the factors were highly reliable in the current study, with Cronbach's alphas of .87 (Psychological Safety) and .85 (Psychological Meaningfulness).

\section{Data Analysis}

We used descriptive statistics to examine the reported likelihood of QRPs and RCR among counselor educators (Research Question 1). We used an analysis of variance (ANOVA) to examine the differences among tenuretrack and non-tenure-track counselor educators and research integrity (Research Question 2). We implemented a path analysis in LISREL 8.72 (Jöreskog \& Sörbom, 2005) to examine the relationships between departmental psychological safety and meaningfulness, life stressors, perceived stress, and research ethics training and participants' RCR behavior (Research Question 3). Path analysis allows for more precise testing of relationships and consideration of spurious associations. We handled missing data for the path analysis with full information maximum likelihood (FIML; for an introduction to FIML, see Enders, 2001). FIML uses all available data to estimate model parameters and is conceptually related to using pairwise available cases. Because of using FIML, responses from all 187 participants contributed to model results. This sample size is generally considered a medium-sized data set for path analysis (Kline, 2005).

\section{Results}

Counselor educator faculty members from research universities indicated that, in the past 2 years, on average, they had published 7.54 articles, books, or other formats of publications $(S D=9.41$, range $=$ 0 to 112 ) and had conducted 7.98 presentations or workshops (SD $=6.61$, range $=0$ to 54). On average, counselor educators indicated spending approximately 8.20 hours per week $(S D=5.49)$ mentoring students and 4.84 hours per week $(S D=4.03)$ advising students. Faculty members had been at their current universities for approximately 4.84 years $(S D=4.03)$. Of those who responded and were on the tenure track, 61 counselor educators $(32.6 \%)$ indicated they were currently seeking tenure. Of these 61 counselor educators, the average amount of years until tenure was $2.55(S D=1.61$, range $=0$ to 5.5). The majority of educators indicated that they had been trained in research ethics $(76.5 \%)$. Of those trained, the most common training method was in their graduate programs (60\%), although $37 \%$ reported that they received research ethics training in a workshop and $27 \%$ at a conference. Another $15 \%$ indicated that they received another method of training, which included teaching it in their own classes, Collaborative Institutional Training Initiative training courses, IRB training, or other literature and web-based resources. 


\section{Self-Reported Likelihood of Engaging in QRPs and RCR}

The overall average score received by this sample of research university counselor educators on the RCRM was $214.97(S D=15.84)$, with a range from 151 to 247 . To make sense of the total sum score, we made a linear transformation from the total RCRM score to the Likert-type scale score (i.e., dividing the total score by the number of items on the measure), resulting in scores ranging from 1 to 6 . Thus, the overall average score on the RCRM converts to 5.12 (i.e., 214.97 divided by 42), which equates to an average response between very likely (5) and extremely likely (6). In addition, more than half (66.4\%) of the faculty members' average converted RCRM scores were between 5.00 and 5.88 , with no one averaging a perfect score of 6.00 . Nearly one third (32.9\%) had average converted RCRM scores between 4.02 and 4.98 (between somewhat likely and very likely), with only one person having an average converted RCRM score of 3.60 (between somewhat unlikely and somewhat likely). No counselor educators had average converted RCRM scores lower than 3.00. This indicates that overall, counselor educators in this sample are likely of engaging in RCR, with a few behaviors potentially deviating from acceptable practices.

An examination of individual items on the RCRM revealed a few specific research behaviors in which research university counselor educators might deviate from acceptable research practices. Depending on the specific behavior, $1 \%(n=2)$ to $73.8 \%(n=138)$ of participants were unlikely to follow acceptable research practices. This was indicated by faculty members self-reporting extremely unlikely (1) or very unlikely (2) on specific items on the RCRM. For example, regarding the confidentiality of research participants, most counselor educators indicated that they would be very likely or extremely likely to remove human participant identification from a database before sharing it with another person outside of the research project ( $n=166,89 \%$ ); however, 15 counselor educators $(8 \%)$ indicated that they would be very unlikely or extremely unlikely to remove these identifiers before providing the database to someone else. Six educators (3.2\%) indicated that they would be very unlikely or extremely unlikely to remove human participant identification before publishing or presenting the data.

The majority of counselor educators indicated that they would discuss authorship and publication rights with students and colleagues before engaging in the project ( $n=151,80.7 \%$ ), whereas 28 faculty members $(15 \%)$ indicated that they would be very unlikely or extremely unlikely to have these conversations. Some faculty members indicated that they would insist on being the senior author in a student's paper (e.g., master's thesis, dissertation, other research paper): $12.8 \%$ indicated somewhat likely to insist, $1.1 \%$ very likely, and $1.6 \%$ extremely likely. One educator stated that it would be an unwritten rule to always be senior author when writing a paper with a student, regardless of the student's contributions.

Although the majority of counselor educators indicated that they would abide by the IRB standards and report any alterations to 
methodology or extend the IRB standards when collecting data, a few counselor educators reported that they would be extremely unlikely to provide these updates $(2.7 \%$ and $3.2 \%$, respectively). Thirteen educators $(7 \%)$ indicated they would be very unlikely or extremely unlikely to get parental consent before asking minors to assent to take part in a study. When examining items that measure behaviors that would be considered research misconduct, we found that a few outliers among the counselor educators existed, indicating that they would be likely to engage in such behavior. For example, six educators (3.2\%) reported being very likely or extremely likely to falsify data on a project to get an article published to lengthen their vita for promotion and tenure, and five educators $(2.7 \%)$ indicated that they would be likely or extremely likely to falsify data, such as reporting that some finding was significant when it was not, to get a grant funded.

\section{Differences Between Tenure-Track Status and RCR}

We used an ANOVA with post hoc Scheffé to explore whether significant differences existed between counselor educators who were seeking tenure, who were tenured, and who were not on the tenure track and their self-reported likelihood to engage in RCR. We found a significant difference, $F(2,125)=4.76, p=.01, \eta^{2}=.07$. Post hoc Scheffé indicated that significant differences existed between counselor educators who were seeking tenure $(M=211.17, S D=14.05)$ and those who were tenured $(M=219.15, S D=15.05)$, with the tenured individuals reporting a greater likelihood to engage in RCR. We note that although we found this significant difference, seeking tenure versus tenured accounts for only $7 \%$ of the variance in RCRM. We found no significant differences between these two groups and those not on the tenure track $(M=209.83, S D=19.52)$.

\section{Correlates of RCR}

The path analysis model fit the data extremely well $\left(\chi^{2}=4.33, d f=9\right.$, $p=.89$, root mean square error of approximation $=0.00$; see Figure $1)$, with the total amount of explained variance for $\mathrm{RCR}$ at $18 \%\left(R^{2}=\right.$ .18). Psychological safety and stressful live events were significantly related to perceived stress $\beta=-.36$ and .29 , respectively; see Table 1 and Figure 1), which indicated that counselor educators felt supported by their departments or department chairs, felt they contributed to their departments, and felt their roles were clearly identified. They perceived less stress; however, as their amounts of various life stressors (e.g., marriage, divorce, illness) increased, so did their levels of perceived stress. According to this path model, psychological safety and stressful live events predicted perceived stress, but did not directly influence RCR. Whereas these two variables explained the levels of perceived stress, we found that this was the only relationship that was nonsignificant in relation to RCR $(\beta=-.14, p>.05$; see Table 1 ; these can be interpreted as regression coefficients). All other variables were significantly related to the dependent variable (i.e., RCR). However, psychological 


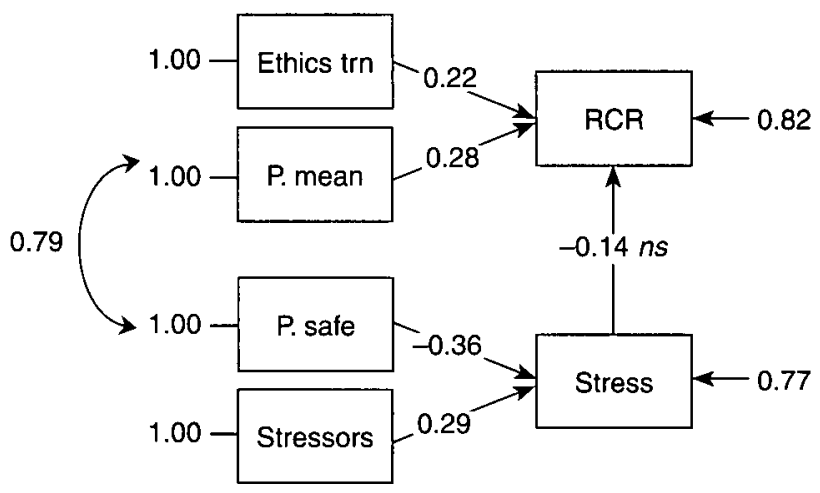

FIGURE 1

\section{Path Model Examining the Relationship With Responsible Conduct of Research (RCR)}

Note. The abbreviation $n s$ indicates an estimated path is not significant (i.e., $p>.05$ ). Psychological safety ( $P$. safe) was allowed to correlate with psychological meaningfulness ( $P$. mean) in acknowledgment of their common focus on departmental climate. $\chi^{2}=4.33, d f=9, p=.89$, root mean square error of approximation $=0.00$. Ethics $\operatorname{trn}=$ training in research ethics; Stress $=$ perceived stress; Stressors $=$ stressful life events.

meaningfulness and training in research ethics were significantly and positively related to RCR $(\beta=.28$ and .22 , respectively, $p<.05)$. This finding suggests that as educators feel recognized and are contributing within their departments and as they receive more training in research ethics, the more likely they will be to engage in RCR.

\section{TABLE 1}

Correlates of Responsible Conduct of Research (RCR) in the Path Analysis $(N=187)$

\begin{tabular}{|c|c|c|c|c|c|c|}
\hline Variable & $\begin{array}{l}\text { Perceived } \\
\text { Stress }\end{array}$ & $\begin{array}{l}\text { Psych. } \\
\text { Safety }\end{array}$ & $\begin{array}{l}\text { Psych. } \\
\text { Meaning }\end{array}$ & $\begin{array}{c}\text { Training } \\
\text { Research }\end{array}$ & Stressors & $\boldsymbol{A}^{e}$ \\
\hline \multicolumn{6}{|l|}{ Estimated coefficient } & 0.18 \\
\hline Standard error $(S E)$ & 0.25 & & 0.15 & 3.10 & & \\
\hline Ratio of EC to $S E$ & -1.59 & & 3.23 & 2.76 & & \\
\hline $\begin{array}{l}\text { Standardized } \\
\text { coefficient }\end{array}$ & \multicolumn{5}{|c|}{ Standardized } & \\
\hline \multicolumn{7}{|l|}{ Perceived stress } \\
\hline $\begin{array}{l}E C \\
S E\end{array}$ & - & $\begin{array}{r}-0.15 \\
0.03\end{array}$ & - & - & $\begin{array}{l}1.39 \\
0.32\end{array}$ & 0.23 \\
\hline $\begin{array}{l}\text { Ratio of EC to } S E \\
\text { Standardized }\end{array}$ & & -5.32 & & & 4.28 & \\
\hline coefficient & & -0.36 & & & 0.29 & \\
\hline
\end{tabular}

Note. The abbreviation $n s$ indicates an estimated path is not significant (i.e., $p>.05$ ). The ratio of $E C$ to $S E$ should be interpreted as a $z$ score. RCR was the dependent variable of interest. Psychological safety (Psych. Safety) and stressful life events (Stressors) were regressed onto perceived stress because of previous relationships found in correlations. A dash indicates that the model parameter was fixed to zero and not estimated. Psych. Meaning = psychological meaningfulness; Training Research $=$ training in research ethics.

a $\mathrm{No}=0$ and yes $=1$. 


\section{Discussion}

Overall, in this study, the majority of counselor educator faculty members from research universities reported that they would be at least very likely to engage in RCR (66.4\%), nearly one third that they would be at least somewhat likely (32.9\%), and one individual that he or she would be between somewhat unlikely and somewhat likely. The average perceived likelihood of GRP and research misconduct in the current sample is lower than the estimated prevalence of $10 \%$ to $40 \%$ of the general research community (Steneck, 2003). Although this finding may bode well for counselor educators in this sample, we note that deviations from accepted research practices were also reported, reflected in the $1 \%$ to $73.8 \%$ of participants indicating they would depart from RCR under certain circumstances. Although this range is wide, we found that the results seemed dependent on the seriousness of the deviation. For example, fewer counselor educators indicated the likelihood to deviate from behaviors representing research misconduct (e.g., falsification of data), but more counselor educators indicated the likelihood to engage in minor QRPs (e.g., not having conversations with colleagues concerning authorship, providing ghost authorship).

The difficulty with counselor educators engaging in QRPs and research misconduct, regardless of how minimal, is the violation of human participant rights (e.g., students, clients) and the unacceptable model of research behavior provided to students. According to Hill (2004), instructors indicated that modeling of faculty members was a primary manner of conveying and teaching ethics, with the second most common method used being the infusion of general ethics training into research courses. Thus, the influence of a counselor educator who engages in unethical research behavior has the potential to be multiplied across students within that educator's department, resulting in students learning inappropriate and unethical research behaviors (Anderson, 1996) that they may take into their future careers. Because of these reasons and potential for poor modeling, Heitman, Anestidou, Olsen, and Bulger (2005) advised educators not to rely solely on modeling and mentorship to relay ethical behavior. Therefore, training research ethics may be a more appropriate way to impart this information.

Although teaching may be a more effective or appropriate way to train students in research ethics, this approach rarely seems to be done. For example, we found that the majority of publications that discussed ethical issues in counseling related primarily to clinical practice, with minimal attention to research ethics (e.g., Corey, Corey, \& Callanan, 2003; Garcia, Cartwright, Winston, \& Borzuchowska, 2003; Welfel \& Lipsitz, 1983). In addition, when counselor educators were asked about how they teach ethics in counseling, Hill (2004) found that only three of 71 counselor educators $(4.2 \%)$ reported they taught research ethics as part of their ethics courses and that research ethics constituted only $4.2 \%$ of the time those three spent on ethics in their courses. Even though the Council for Accreditation of Counseling and Related Educational Programs (2001, 2009) 
has indicated that research ethics should be included as part of the core curriculum, we found that ethics seem to be a neglected area in counselor education instruction. This begs the question of the value that incoming professionals and doctoral students are receiving on the importance of research integrity.

Yet according to the results in this study, training in research ethics was significantly, positively related to engaging in RCR. These results support the method of teaching for instilling ethical values. Roth (2002) reported instructors should keep five main objectives in mind when teaching research ethics: helping students gain the knowledge of research ethics, helping change attitudes to accept and foster responsibility to adhere to ethical behavior, instilling and creating new skills to assist students in recognizing ethical situations, altering students behaviors so they take appropriate action when they do recognize an ethical situation, and informing students of the influence research can have on the community and human participants.

Regarding Roth's (2002) recommendations, Wester (2007) discussed specific methods of incorporating research ethics into the classroom, with some examples being to use video or web-based vignettes (e.g., Bebeau \& Thoma, 1994; Self, Olivarez, \& Baldwin, 1998; Wester, 2005). Teaching research ethics could be incorporated into classes such as professional orientation, clinical courses such as practicum and internship (when discussing how to collect data on clients to determine effectiveness), assessment class (ethics in using instrumentation in practice), or a specific research class designed for master's- or doctoral-level students. Through teaching research ethics, counselor educators may refamiliarize themselves with the research ethical codes to train their students. According to the results of the path model in this study, this refamiliarizing may increase RCR, ultimately leading to counselor educators being good models for students in the area of research behaviors.

Although training is important, we struggle to understand the reasons for the few individuals who deviate from RCR. Some potentially related factors may be faculty members still seeking tenure are less likely to practice RCR than are those who already have tenure or are not under the pressure of tenure and the psychological meaningfulness of one's department positively relates to research integrity. The latter suggests that counselor educators who feel challenged in their jobs, feel they contribute to their departments or professions, and receive recognition for the work they produce tend to be more likely to engage in RCR. However, those faculty members who do not feel challenged, do not feel their work makes a contribution, or are not recognized for their achievements and contributions are less likely to engage in research integrity. Therefore, some portion of QRPs can be explained by the meaningfulness perceived in the job and within the department. This seems to relate to what Martinson et al. (2006) found when examining NIH researchers' environments. They discovered that researchers who felt treated unfairly within their environment were more likely than others to engage in QRPs. 
With the understanding that psychological meaningfulness contributed to RCR and that faculty members at research institutions seeking tenure are more likely to depart from RCR, it would be important for department chairs and other faculty members to support tenureseeking faculty members in becoming comfortable in their roles as educators, service providers, and researchers. This support can come through flexibility in assignments and roles, as well as recognition of the contributions of early career educators. More specifically, Rice, Sorcinelli, and Austin (2000) provided specific guidelines for helping new faculty members thrive in their academic careers. Their recommendations included behaviors such as providing clear communication and expectations for performance, specifically regarding promotion and tenure. This may help new faculty members in understanding what they need to do to receive promotion and tenure at their institutions.

Rice et al. (2000) also indicated the importance of providing feedback on faculty member performance. This may be a way to help counselor educators feel they have contributed to the department and recognize

- whether their contributions are valued. Rice et al. discussed the need to mentor new faculty members and the need for strong and valuable connections of junior members to senior members, including the areas of teaching and research. This has become evident in some other studies conducted specifically among counselor educators (e.g., Briggs \& Pehrsson, 2008; Magnuson, Norem, \& Lonneman-Doroff, 2009). Briggs and Pehrsson (2008) examined pretenured counselor educators and found, among other things, that only 30\% reported their mentoring relationships focused on their actual needs. This leaves $70 \%$ of counselor educators who did not report such a focus. Magnuson et al. (2009) followed a cohort of assistant counselor educators for 6 years and found that those who were successful or satisfied reported good collegial relationships, enjoyed their jobs (e.g., teaching was important), recognized their contributions (e.g., student success), and felt they had made contributions to the profession. These all speak to the idea of psychological meaningfulness within one's department and role as a counselor educator.

The lack of a significant relationship between levels of perceived stress and RCR suggests that stress alone did not influence RCR. Therefore, researchers in high-stress situations were not necessarily more likely to engage in GRPs. However, this finding may also relate more to individuals' abilities to manage stress, not just their levels of perceived stress.

\section{Limitations}

Some limitations to the current study need to be noted. Specifically, although we obtained a $37.8 \%$ response rate from a nationwide sample of counselor educators from research universities, we acknowledge that a large portion of the sample and counselor educators were not included in the study (e.g., those that did not respond, counselor educators from nonresearch universities). Therefore, precautions should be taken in generalizing these results. It should be noted that the 
$37.8 \%$ response rate might be because of collecting data using only one method (i.e., web-based survey). However, in a meta-analysis of Internet-based research, Cook, Heath, and Thompson (2000) indicated that the mean response rate for online surveys was $39 \%$.

A second limitation of the current study is social desirability. Randall and Fernandes (1991) reported that socially desirable responding strongly influenced self-reported ethical behavior. Thus, counselor educators in the current study may have responded in a socially desirable manner, which resulted in higher levels of responsible conduct of behavior. However, even with the potential for socially desirable responses, some deviations of research ethical behavior were reported; thus, the estimates of QRPs and research misconduct in this study could be considered to be conservative.

\section{Future Research}

Whereas this study was one of the first in examining RCR that incorporated individual, situational, and organizational factors in attempting to better understand ethical research behaviors, we acknowledge that we did not include all variables. With $18 \%$ of RCR explained by our current path analysis, we believe that more can be learned concerning factors that influence research ethics. Our current results suggest that environmental factors and background training may be fruitful areas for further investigation. Other factors to consider include exploring moral character, whether individuals are honest or adhere to ethical standards outside of research, or whether individuals tend to feel more entitled and deviate from acceptable practices when it best fits them, as suggested by Rest and Narváez (1994). In addition, previous researchers have found feelings of entitlement to be related to RCR (e.g., Davis et al., 2008), which was not included in the current study. In addition, other factors such as stress management or interpersonal relationships might be examined. It would be helpful to understand the longitudinal nature of these relationships, noting the potential influence that research ethics training may have on individuals' research behaviors and that stress management or psychological climate may have on altering how ethical knowledge transfers into behaviors across time. In addition, conducting a more in-depth qualitative case study of the one counselor educator in the current study who reported being more likely to deviate from acceptable research practices would be helpful to gain a better understanding of individual, situational, or organizational circumstances and factors that play a role in research behaviors.

\section{Conclusion}

The significant influence of research ethics training on RCR has promising implications for practice. These results suggest that value exists in offering formal research ethics training to professional researchers, students, practitioners, or educators, with the potential for the latter to model ethical behavior for students. In addition, aspects of one's department seem to be influential and can be easily altered, includ- 
ing recognition for a job well done; giving written or verbal feedback; and creating an environment that is challenging, yet rewarding. Although these do not seem to be daunting or even complex tasks, they were related to the likelihood of faculty members engaging in RCR in the current sample. Therefore, although counselor educators seem unlikely to engage in QRPs, we believe that the risk could be further reduced by altering aspects of departmental environment and by providing training. The few educators who engage in GRPs and research misconduct are not appropriate ethical role models for students. Therefore, steps need to be taken to minimize these unethical behaviors and promote RCR.

\section{References}

American Counseling Association. (2005). ACA code of ethics. Retrieved from http:// www.counseling.org/Resources/CodeOfEthics/TP/Home/CT2.aspx

Anderson, M. S. (1996). Misconduct and departmental context: Evidence from the Acadia Institute's Graduate Education Project. Journal of Information Ethics. $5,15-33$.

Anderson, M. S., Louis, K. S., \& Earle, J. (1994). Disciplinary and departmental effects on observations of faculty and graduate student misconduct. Journal of Higher Education, 65, 331-350.

Bebeau, M. J., \& Thoma, S. J. (1994). The impact of a dental ethics curriculum on moral reasoning. Journal of Dental Education, 58, 684-692.

Briggs, C. A., \& Pehrsson, D.-E. (2008). Research mentorship in counselor education. Counselor Education and Supervision, 48, 101-113.

Brown. S. P., \& Espina, M. R. (2000). Report of the ACA ethics committee: 19981999. Journal of Counseling \& Development, 78, 237-241.

Brown, S. P., \& Leigh. T. W. (1996). A new look at psychological climate and its relationship to job involvement, effort, and performance. Journal of Applied Psychology, 81, 358-368.

Carnegie Foundation for the Advancement of Teaching. (n.d.). Classification description: Basic classification. Retrieved from http://classifications.carnegiefoundation. org/descriptions/basic.php

Cohen, S., Kamarck, T., \& Mermelstein, R. (1983). A global measure of perceived stress. Journal of Health and Social Behavior, 24, 385-396.

Converse, J. M., \& Presser, S. (1986). Survey questions: Handcrafting the standardized questionnaire. Beverly Hills, CA: Sage.

Cook, C., Heath, F., \& Thompson, R. L. (2000). A meta-analysis of response rates in web- or Internet-based surveys. Educational and Psychological Measurement, 60, 821-836.

Corey, G., Corey, M. S., \& Callanan, P. (2003). Issues and ethics in the helping professions (6th ed.). Pacific Grove, CA: Brooks/Cole/Thomson Learning.

Council for Accreditation of Counseling and Related Educational Programs. (2001). 2001 standards. Retrieved from http://www.cacrep.org/doc/2001\%20 Standards.pdf

Council for Accreditation of Counseling and Related Educational Programs. (2009). 2009 standards. Retrieved from http://www.cacrep.org/doc/2009\%20 Standards.pdf

Davis. M. S.. Riske, M. L., \& Seaman, M. (2001). Research misconduct: An inquiry into etiology and stigma. Amherst, $\mathrm{OH}$ : Justice Research and Advocacy.

Davis, M. S., Wester, K. L., \& King, B. (2008). Narcissism, entitlement, and questionable research practices in counseling: A pilot study. Journal of Counseling \& Development, 86, 200-210.

De Vries, R. Anderson, M. S., \& Martinson, B. C. (2006). Normal misbehavior: Scientists talk about the ethics of research. Journal of Empirical Research on Human Research Ethics, 1, 43-50.

Enders. C. K. (2001). A primer on maximum likelihood algorithms available for use with missing data. Structural Equation Modeling, 8, 128-141. 
Garcia, J. G., Cartwright, B., Winston, S. M., \& Borzuchowska, B. (2003). A transcultural integrative model for ethical decision making in counseling. Journal of Counseling \& Development, 81, 268-277.

Heitman, E., Anestidou, L., Olsen, C., \& Bulger, R. E. (2005). Do researchers learn to overlook misbehavior? Hastings Center Report, 35, 49.

Hill, A. L. (2004). Ethics education: Recommendations for an evolving discipline. Counseling and Values, 48, 183-203.

Jöreskog, K., \& Sörbom D. (2005). LISREL 8.72 for Windows [Computer software]. Lincolnwood. IL: Scientific Software International.

Kahn, W. A. (1990). Psychological conditions of personal engagement and disengagement at work. Academy of Management Journal, 33, 692-724.

Kiewitz, C., Hochwarter, W. A., Ferris, G. R., \& Castro, S. L. (2002). The role of psychological climate in neutralizing the effects of organizational politics on work outcomes. Journal of Applied Social Psychology, 32, 1189-1207.

Kline, R. B. (2005). Principles and practice of structural equation modeling (2nd ed.). New York, NY: Guilford Press.

Kocet, M. M., \& Freeman, L. T. (2005). Report of the ACA ethics committee: 2003-2004. Journal of Counseling \& Development, 83, 249-252.

Magnuson, S., Norem, K., \& Lonneman-Doroff, T. (2009). The 2000 cohort of new assistant professors of counselor education: Reflecting at the culmination of six years. Counselor Education and Supervision, 49, 54-71.

Martinson, B. C., Anderson, M. S., Crain, A. L., \& De Vries, R. (2006). Scientists' perceptions of organizational justice and self-reported misbehaviors. Journal of Empirical Research on Human Research Ethics, 1, 51-66.

Mumford, M. D., Connelly, M. S., Helton, W. B., Strange, J. M., \& Osburn, H. K. (2001). On the construct validity of integrity tests: Individual and situational factors as predictors of test performance. International Journal of Selection and Assessment, 9, 240-257.

Mumford, M. D., \& Helton, W. B. (2002). Organizational influences on scientific integrity. In N. H. Steneck \& M. D. Scheetz (Eds.), Investigating research integrity: Proceedings of the first ORI research conference on research integrity (pp. 73-90). Retrieved from U.S. Department of Health and Human Services, Office of Research Integrity website: http://ori.dhhs.gov/documents/proceedings_rri.pdf

Randall, D. M., \& Fernandes, M. F. (1991). The social desirability response bias in ethics research. Journal of Business Ethics, 10, 805-817.

Rees, L. H. (2001). Fraud and misconduct in medical research: Prevention. In S. Lock, F. Wells, \& M. J. G. Farthing (Eds.), Fraud and misconduct in biomedical research (3rd ed., pp. 225-243). London, England: BMJ Books.

Rest, J. R., \& Narvâez, D. (Eds.). (1994). Moral development in the professions: Psychology and applied ethics. Hillsdale, NJ: Erlbaum.

Rice, R. E., Sorcinelli, M. D., \& Austin, A. E. (2000). Heeding new voices: Academic careers for a new generation. Washington, DC: American Association for Higher Education.

Roth. C. (2002). Why teach research ethics? Retrieved from Resources for Research Ethics Education website: http://research-ethics.net/introduction/why/\#summary

Sanders, J.-A. L., \& Freeman, L. T. (2003). Report of the ACA ethics committee: 2001-2002. Journal of Counseling \& Development, 81, 251-254.

Scully, J. A., Tosi, H., \& Banning, K. (2000). Life event checklists: Revisiting the Social Readjustment Rating Scale after 30 years. Educational \& Psychological Measurement, 60, 864-877.

Self, D. J., Olivarez, M., \& Baldwin, D. C., Jr. (1998). Clarifying the relationship of medical education and moral development. Academic Medicine, 73, 517-520.

Steneck, N. H. (2003). The role of professional societies in promoting integrity in research. American Journal of Health Behavior, 27(Suppl. 3), S239-S247.

Steneck, N. H. (2006). Fostering integrity in research: Definitions, current knowledge, and future directions. Science \& Engineering Ethics, 12, 53-74.

U.S. Department of Health and Human Services, National Institutes of Health. Office of Extramural Research. (2002). Research on research integrity (RFA No. NS-03-001). Retrieved from http://grantsl.nih.gov/grants/guide/rfa-files/ RFA-NS-03-001.html 
U.S. Department of Health and Human Services, Office of Research Integrity. (2000). PHS policy on instruction in the responsible conduct of research (RCR). Retrieved from http://ori.hhs.gov/policies/RCR_Policy.shtml

Welfel, E. R., \& Lipsitz, N. E. (1983). Wanted: A comprehensive approach to ethics research and education. Counselor Education and Supervision, 22, 320-332.

Wester, K. L. (2005). Conducting research responsibly: Cases for counseling professionals [Handbook and DVD]. Greensboro, NC: Author and the National Board for Certified Counselors.

Wester, K. L. (2007). Teaching research integrity in the field of counseling. Counselor Education and Supervision, 46, 199-211.

Wester. K. L.. Willse, J. T., \& Davis, M. S. (2008). Responsible Conduct of Research Measure: Initial development and pilot study. Accountability in Research: Policies and Quality Assurance, 15, 87-104. 
Copyright of Counselor Education \& Supervision is the property of American Counseling Association and its content may not be copied or emailed to multiple sites or posted to a listserv without the copyright holder's express written permission. However, users may print, download, or email articles for individual use. 